\title{
FRICTION WELDING OF STEEL TO CERAMIC
}

\author{
P. Rombaut ${ }^{1}$, W. De Waele ${ }^{2}$ and K. Faes ${ }^{3}$ \\ ${ }^{1}$ Ghent University, Belgium \\ ${ }^{2}$ Ghent University, Laboratory Soete, Belgium \\ ${ }^{3}$ Belgian Welding Institute, Belgium
}

\begin{abstract}
The goal of this paper is to give a clear summary of the literature review performed during the master thesis on friction welding on dissimilar materials. Of main interest for this work is the welding of steel to a ceramic material such as alumina $\left(\mathrm{Al}_{2} \mathrm{O}_{3}\right)$. Because of the difficulties involved in producing a sound weld for this material combination, not a lot of literature is available on this topic. This paper starts with a discussion on the basics of friction welding and typical problems encountered in welding of steel to ceramic.

Almost all research articles that have been found in open literature state that welding steel to a ceramic is nearly impossible without using an interlayer consisting of a compatible metal. The most frequently reported type of weld is steel to alumina with an aluminium interlayer. For this reason the literature study included in this thesis, also focuses on friction welding of aluminium to steel and aluminium to ceramic. A detailed explanation will be given for the most challenging difficulties like the creation of a brittle intermetallic compound layer in a steel-aluminium weld interface and the creation of fatal thermally induced stresses in an aluminium-ceramic weld interface. Both of these problems must be dealt with in order to produce a strong bond. A redesigned rotary friction welding machine is currently being assembled and will be used for the experimental part of this research.
\end{abstract}

Keywords friction welding, ceramics, steel, aluminium

\section{INTRODUCTION}

The main objective of the thesis is to investigate the possibility of joining dissimilar materials by means of friction welding. The material combination that will be studied in detail consists of steel and ceramic material. At first, a literature study has been conducted to get a basic understanding of the principles of friction welding, and of the physical phenomena which are important in welding steel to ceramics. This specific material combination is relatively new, but has a lot of potential applications in today's industry.

In the modern industry, there is a constant drive to make everything lighter, stronger and more durable. The studied material combination combines the strength, high ductility and toughness, and adaptability of steel with the advantages of technical ceramics, such as high hardness, wear resistance, chemical inertness, corrosion resistance, low thermal expansion coefficient and resistance to high temperatures. This ensemble of properties is especially useful in area's like the automotive, aerospace, electronics, and nuclear industries.

Friction welding is a solid state welding process that allows joining of specific material combinations which are considered unweldable by conventional techniques. In order to produce a friction weld, the two components are forced to rotate against each other (friction phase), thereby generating heat at the interface. Once the desired upset length or process time has been reached, the rubbing motion stops (braking phase), the pressure rises (swelling time) and the components are pressed against each other (forging phase) until they are cooled down. The main variables in friction welding are the rotational speed, the axial forces during the friction and forging phases, and the welding time. The typical relationship of these characteristics is shown in Fig. 1 which illustrates a direct drive friction welding process. 


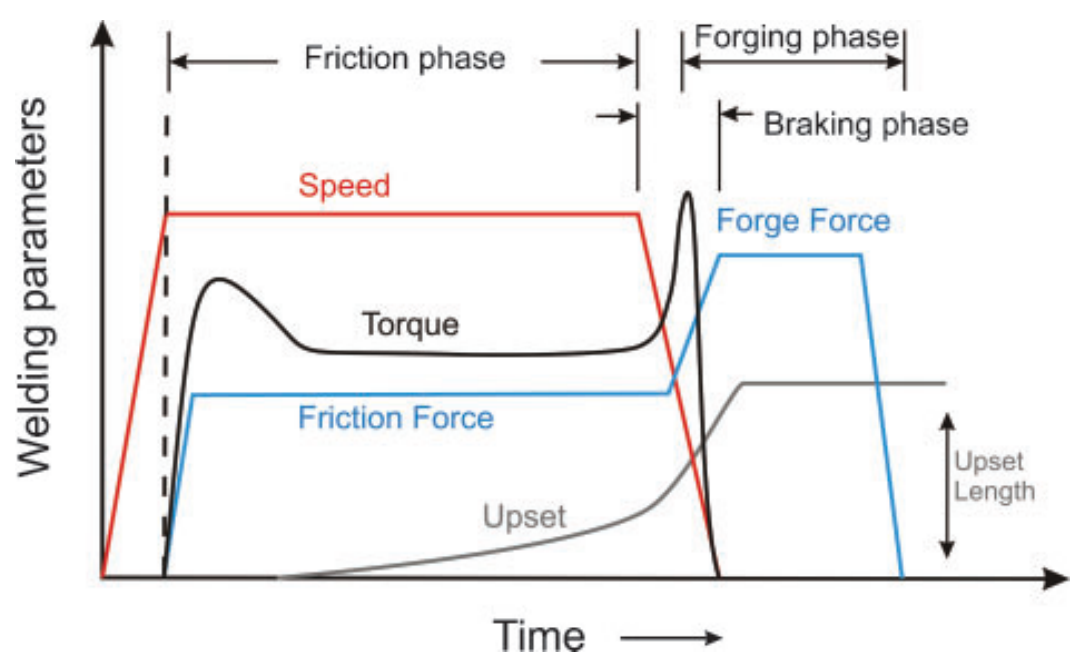

Fig. 1: Variation of the welding parameters with time in direct drive friction welding. (2)

In order to make such a weld, a rotary friction welding machine has been redesigned (see Fig. 2) (2) to meet the specific demands of the material combination steel - ceramic. The final goal of this thesis is to use this machine to make successful welds between metal and ceramic bars and to investigate the integrity and strength of this weld by means of microscopic examination and fracture tests.

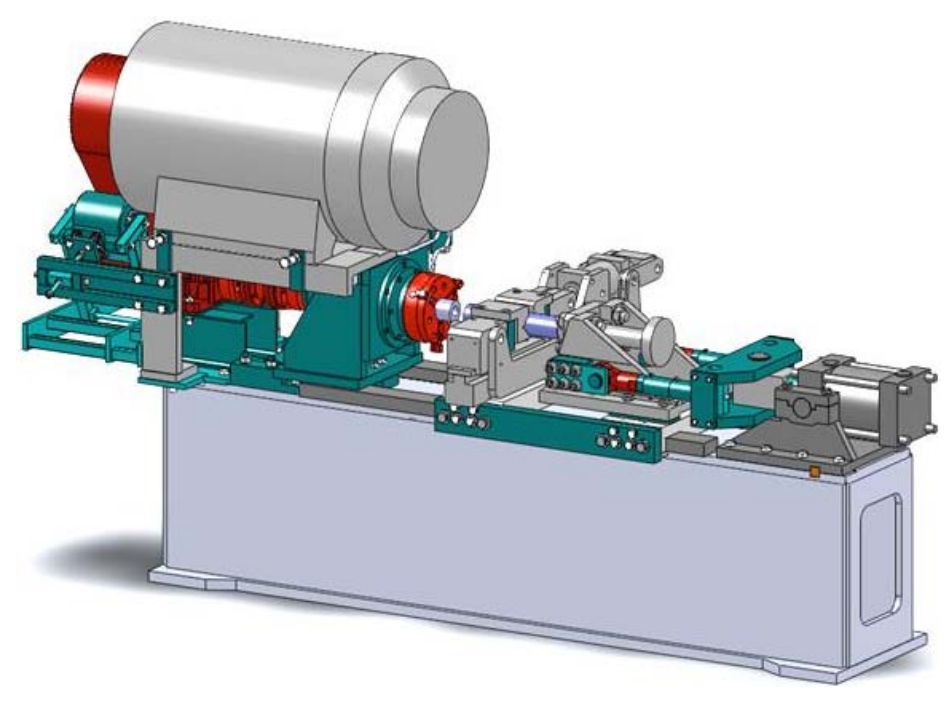

Fig. 2: Redesign of the rotary friction welding machine (2)

\section{CHALLENGES IN FRICTION WELDING OF CERAMIC TO STEEL}

It is not straightforward to make a sound and strong bond between a ceramic material and steel. Sometimes the joint will prematurely break at the interface or in an adjacent area in the ceramic material [ (4) (5)]. This mostly happens during the cooling down phase when cracks initiate and propagate, or during post-welding mechanical treatments. The reasons for this observed fracture behaviour can be attributed to differences in thermal and mechanical properties and in the crystallographic structures of the two materials.

There are three major causes related to the welding problems observed for this material combination:

- There is an important difference in the type of atomic bond between a ceramic and steel. Bonding in ceramics is mainly of an ionic or covalent nature (and usually a hybrid of these), while metals have a metallic bonding character.

- There is often a very big difference in thermal expansion between the two materials. Ceramics typically have a much lower thermal expansion coefficient. When the two parts cool down after welding, this induces thermal stresses at the weld interface which could lead to cracking.

- The brittle and porous nature of ceramics makes it very hard to absorb production defects. The strength of a ceramic is highly dependent of its grain size and surface roughness. (6) 
Despite these problems, joints between steel and ceramics have already been realized successfully trough rotary friction welding [ (3) (5)]. Fig. 9 shows that alumina $\left(\mathrm{Al}_{2} \mathrm{O}_{3}\right)$ and mild steel rods were successfully joined using friction welding at a rotational speed of $900 \mathrm{rpm}$. However a $1 \mathrm{~mm}$ thick aluminum sheet has been used as soft interlayer (5).

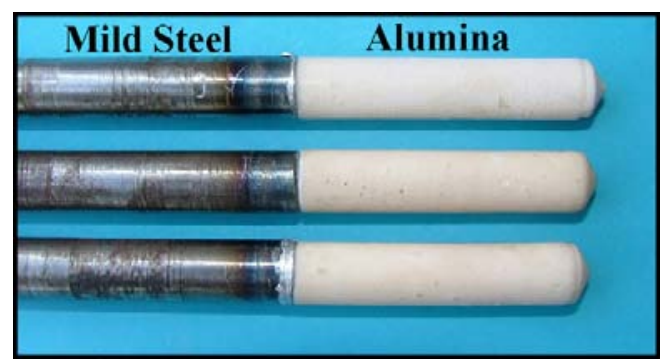

Fig. 3: Successful friction welds of alumina to mild steel (5)

A successful joint almost always contains a stress-relieving metallic interlayer that absorbs the stresses caused by the thermal expansion difference of the two base materials. The aluminum interlayer has been found to be an essential intermediate medium in the formation of a sound joint between alumina and mild steel. It acts as a ductile buffer which is capable of absorbing deformations and stresses related to the high temperature gradient during the cooling phase (5).

Because of the third type of material that is introduced in the welding process, the weld geometry becomes even more complex. The bond now consists of two weld interfaces, namely a steel/aluminium and an aluminium/alumina weld interface. Both of these interfaces need to be free of defects and have a maximum strength in order to optimize the total bond strength.

\section{FRICTION WELDING OF ALUMINIUM TO STEEL}

\subsection{Difficulties}

Joining of aluminium to steel is not easy for the following reasons (6):

- Much higher melting points of steels compared to aluminium alloys.

- Difference between the thermal expansion coefficients of steel and aluminium.

- The very tenacious superficial oxide film on aluminium alloy, which interferes with the achievement of a metal-to-metal contact at the interface.

- The formation of brittle intermetallic compounds (IMC).

The most serious of these problems is the formation of brittle intermetallic compounds (IMC) resulting from the reaction of $\mathrm{Al}$ with $\mathrm{Fe}$. In particular, fusion welding involves the formation of large amounts of intermetallic compounds in the weld metal because the steel and the aluminium alloy are mixed in the liquid state. This material combination is therefore considered to be unsuitable for fusion welding. Friction welding is a process most widely used for joining of dissimilar metals, and for aluminium to steel in particular, because of its high productivity and reliability of the joint performance in addition to the controllability of the formation of the IMC layer. The following paragraph discusses the formation of IMC layers in more detail.

\subsection{Occurrence and growth of the intermetallic compounds in rotary friction welding}

Tylecote (7) stated that the formation of Al-Fe intermetallic compounds at the weld interface causes a serious reduction of the joint strength. Wallach and Elliot (8) (9) suggested by reviewing previous papers that a reduction of the joint strength only occurred when the thickness of the IMC layer exceeded about $1 \mu \mathrm{m}$. They also suggested that the addition of $\mathrm{Mg}$ to the aluminium alloy enhances the growth of the IMC layer and reduces the joint strength, whilst $\mathrm{Si}$ addition retards the growth of the IMC layer and thus improves the joint strength. 
In order to get an improved insight in the growth of the intermetallic compound layer, Yamamoto et al. (10) (11) (12). investigated the nano-scale microstructures of the friction weld interface of aluminium alloys (A5052, A5083 and A1070) to low carbon steel (S10C). For all these weld trials, the tensile strength of the joint had a common tendency to first increase with friction time up to a maximum value, and then to decrease with a further increase in friction time (see Fig. 4). The maximum joint strength obtained, was approximately equal to the tensile strength of the (weakest) base material.

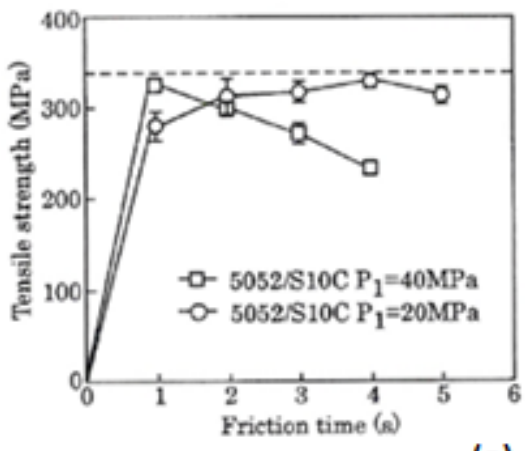

(a)

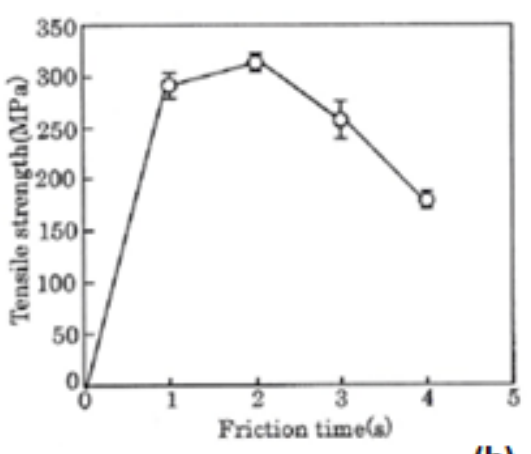

(b)

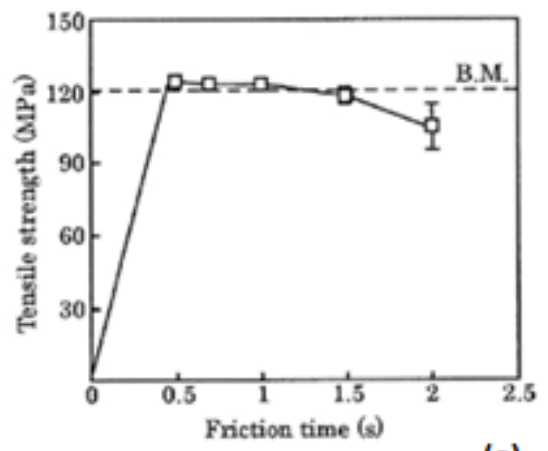

(c)

Fig. 4: Tensile strength vs. friction time for friction welds of steel S10C to aluminium alloys A5052 (a), $A 5083$ (b) and $A 1070$ (c). $P_{1}$ resembles the friction pressure during the friction phase.

\subsubsection{Al-oxide layer}

Observations of the fracture surfaces and interfacial microstructures suggest that an Al-oxide film of $\sim 10 \mu \mathrm{m}$ thickness was present at the joint interface for the shorter friction times (i.e. when the tensile strength increased with friction time, see Fig. 4). The tensile cracks of the test specimens propagated along this oxide film.

Probably this Al-oxide layer originated from the superficial oxide film that gives the Al alloy corrosive resistant properties. Oxide contamination in the interface reduces the quality of the weld. This may be explained in terms of interface impurities, which do not permit a close contact between the base materials, which is necessary to obtain full bonding (13).

\subsubsection{The Al-Fe IMC layer}

When the friction time was longer than the one corresponding to the maximum joint strength (see Fig. 4), the Al-oxide film at the interface was not longer observed. The tensile cracks of the test specimens propagated through the IMC layer, which occupied almost the whole area of the interface. The relation between the tensile strength of the joints and the thickness of the IMC layer is shown in Fig. 5 for the three material combinations.

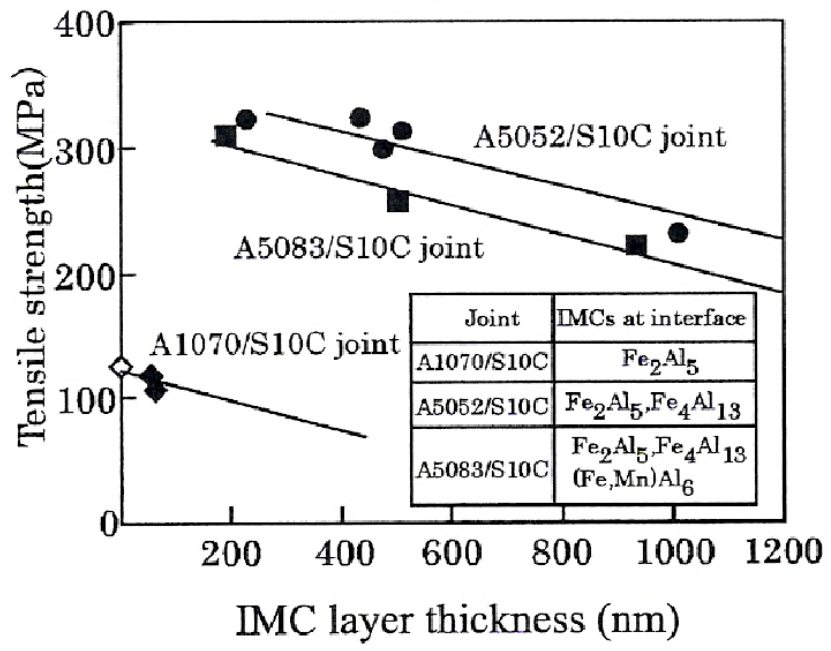

Fig. 5: Relations between the tensile strength and the thickness of the IMC layer for the A5052/S10C, A5083/S10C, and A1070/S10C joints. 
The tensile strength of the joints which fractured in the IMC layer was found to decrease with an increasing thickness of the IMC layer. This thickness increased almost proportionally to friction time at a rate depending on the kind of Al alloy. An increase in the friction pressure was found to enhance the growth rate of the IMC layer. It is clear that in order to produce a sound weld with optimal strength, the thickness of the IMC layer has to be controlled to stay within certain limits. Although the presence of a small amount of intermetallic components seem to be favourable for the weld quality, the thickness of the IMC layer must not exceed the proposed thickness of $1 \mu \mathrm{m}$.

Typical IMC layers observed in the joints of steel to A5052 and A5083 Al alloy and to A1070 pure aluminium, are shown in Fig. 6 (a), (b), and (c), respectively.

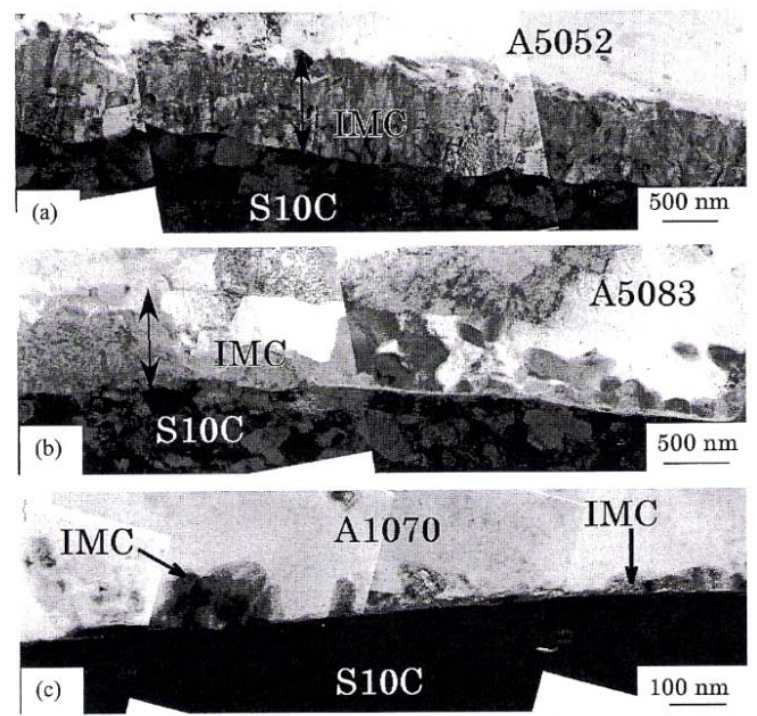

Fig. 6: IMC layers observed at friction-bonded interfaces: (a)A5052/S10C joint $\left(P_{1}=40 M P a, t_{1}=4 S\right)$, (b) A5083/S10C joint $\left(P_{1}=40 M P a, t_{1}=3 s\right)$, and (c) A1070/S10C joint $\left(P_{1}=20 M P a, t_{1}=2 s\right) . t_{1}$ resembles the duration of the friction phase.

\subsection{3 $\mathrm{MgAl}_{2} \mathrm{O}_{4}$ oxide layer}

When the friction time was at its maximum (see Fig. 4), a magnesium-aluminium-oxide layer $\left(\mathrm{MgAl}_{2} \mathrm{O}_{4}\right)$ was formed in addition to the intermetallic compounds. The A5083/S10C joint reached much lower tensile strength than that estimated from the IMC layer thickness and using the relation shown in Fig. 4. This result suggests that the $\mathrm{MgAl}_{2} \mathrm{O}_{4}$ layer impaired the joint strength more seriously than the IMC layer. The presence of this layer can be considered as a cause for the decrease in joint strength when the friction time further increases.

In order to confirm this assumption, the cross section of the fractured surface of a joint welded with a high friction time was observed with TEM. The observed microstructure of the fractured surface (A5083 Al-alloy side) is shown in Fig. 7 .

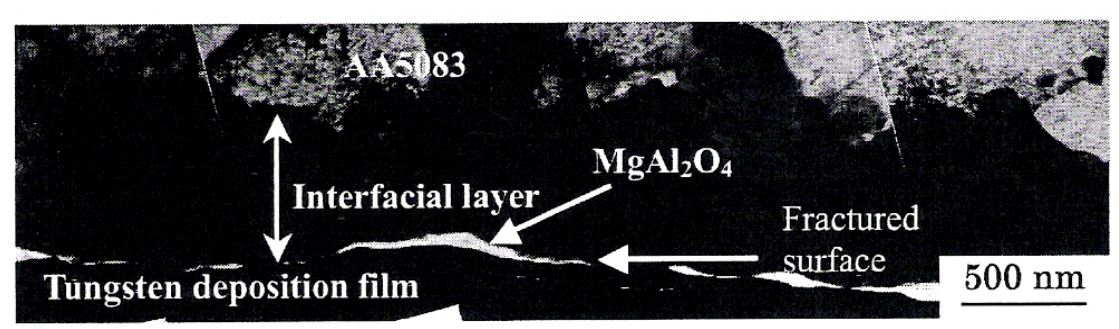

Fig. 7: Fractured surface observed in a joint bonded at friction time of $4 \mathrm{~s}$

This micrograph confirmed that the fracture occurred along the $\mathrm{MgAl}_{2} \mathrm{O}_{4}$ layer, since this layer was observed along the entire fractured surface. For shorter friction times it was observed that the fracture occurred at the Al-oxide layer between the IMC layer and steel substrate $\left(t_{1}=1 \mathrm{~s}\right)$, and along the IMC layer $\left(t_{1}=2 \mathrm{~s}\right)$. 
These microstructures can clearly be considered to be critical factors controlling the bond strength of the joints obtained under the given conditions. Since the bond strength was significantly reduced by an increase in friction time from 2 to $4 \mathrm{~s}$, the $\mathrm{MgAl}_{2} \mathrm{O}_{4}$ layer can be regarded as more harmful to the bond strength than the IMC layer.

\section{FRICTION WELDING OF ALUMINIUM TO CERAMIC}

In order to reach an optimal strength of the weld interface, it is important to keep in mind that the difference in thermal expansion of the two welded pieces needs to be carefully controlled. The stresses induced during cooling down after welding can be sufficient to cause the joint to crack and prematurely fail.

\subsection{Thermally induced stresses.}

To investigate this phenomenon, Zimmerman et al. (13) (14) and R. Weiss (16) have made various finite element simulations of the heat generation throughout the weld pieces and the contact pressure distributions at the weld interface. The workpieces they used for the experimental validation were rods of $10 \mathrm{~mm}$ diameter made of corundum ceramics $\left(97.5 \% \mathrm{Al}_{2} \mathrm{O}_{3}\right)$ and aluminium alloy 6061-T6.

The optimal friction welding conditions that where applied for bonding aluminium alloy 6061-T6 and ceramic $\mathrm{Al}_{2} \mathrm{O}_{3}$ are given in Table 1 and were originally established by Wlosinski et al. (2004) (14).

$\begin{array}{lr}\text { Rotational speed (rpm) } & 14,500 \\ \text { Friction time (ms) } & 850 \\ \text { Swelling time (ms) } & 3,500 \\ \text { Pressure in the friction time (MPa) } & 18 \\ \text { Pressure in the swelling time (MPa) } & 46 \\ \text { Delay time (ms) } & 80\end{array}$

Table 1: Friction welding conditions (Wlosinski et al., 2004) (14)

\subsubsection{Heating phase.}

The temperature distributions at the contact surface for different periods of frictional heating are presented in Fig. 8. Figure 9 shows the temperature distribution in the two joined elements as a function of friction time. It is clear that the temperature is not uniformly distributed over the joint interface. The outer regions of this interface (i.e. the most distant from the axis), remain at a lower temperature for a long time. This might have a negative influence on the quality of the joints in the vicinity of the outer diameter. This is confirmed by observing tensile test specimens, as shown in figure Fig. 11, where the whiter regions represent alumina particles that have been welded to the metal and the more gray regions did not form a strong bond. Also note that a flash is developed in the aluminium workpiece (Fig. 9), which leads to a geometrical discontinuity and stress concentration.

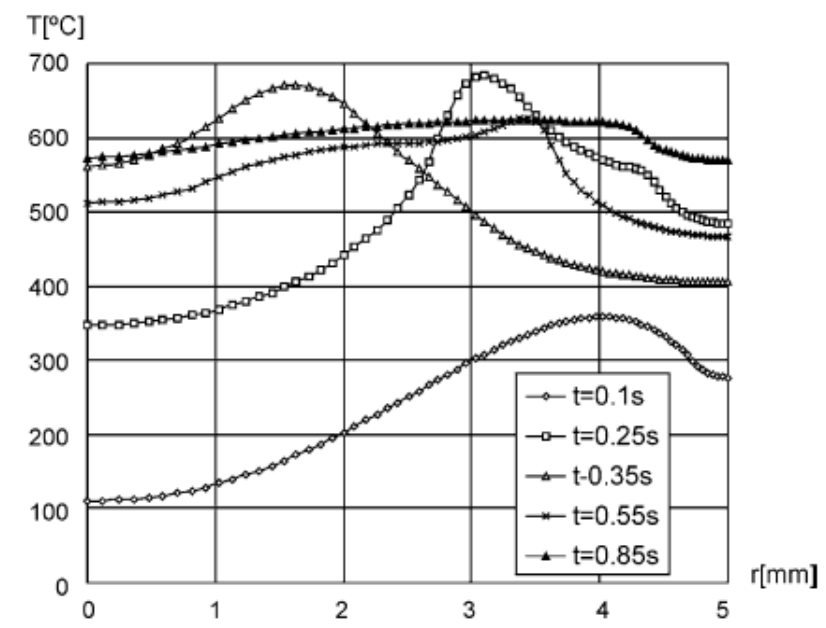

Fig. 8: Temperature variation over the joint interface for selected values of heating time. 

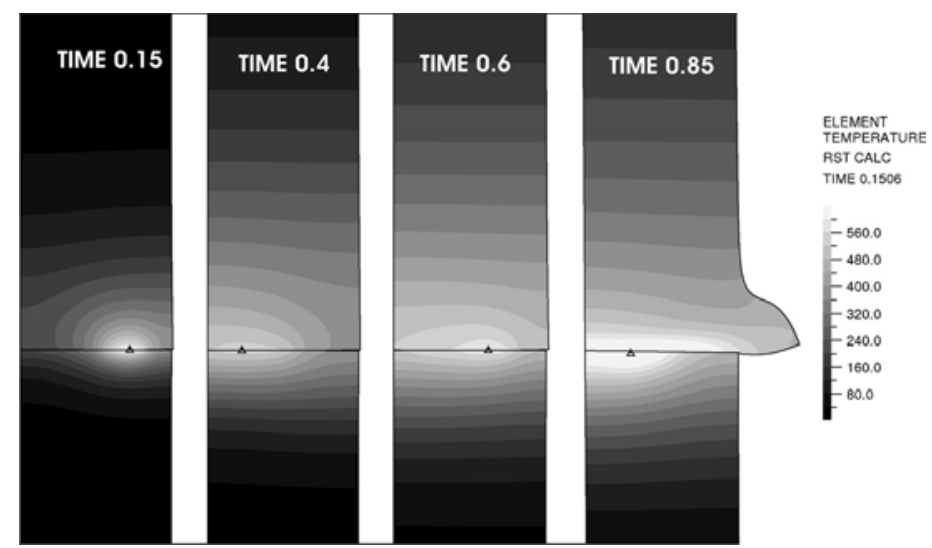

Fig. 9: Temperature distributions in the welded materials for selected values of friction time.

The high temperatures and the applied friction pressure cause local plastic and thermal deformations at the joint interface which mainly occur in the aluminium workpiece. The ceramic does not deform significantly. As a result the actual contact area changes continuously. The heat flux depends on the bearing surface and the temperature dependent friction coefficient. For a heating time of $0.455 \mathrm{~s}$ the deformation (scaled up eight times) of the aluminium workpiece near the welding zone and the distribution of temperature and contact forces (dashed area), is shown in Fig. 10.

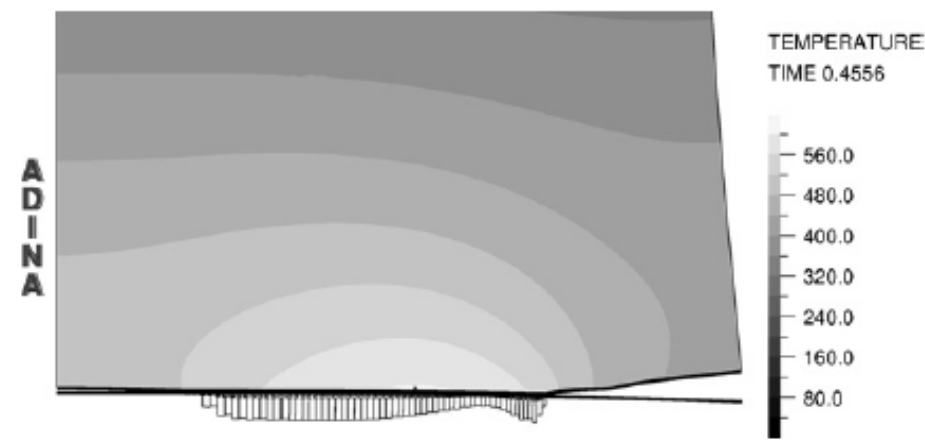

Fig. 10: Deformation of Al in the vicinity of the contact zone scaled up eight times, bands of equal temperature and contact force distribution (time of heating $0.455 \mathrm{~s}$ )

The contact pressure distribution is found to be close to uniform only in the last phase of friction. However, the regions most distant from the axis never come into contact during the friction stage. This means that the bond at these regions may be weaker. The pictures of fractured joints after tensile testing confirm this conclusion (Fig. 11).
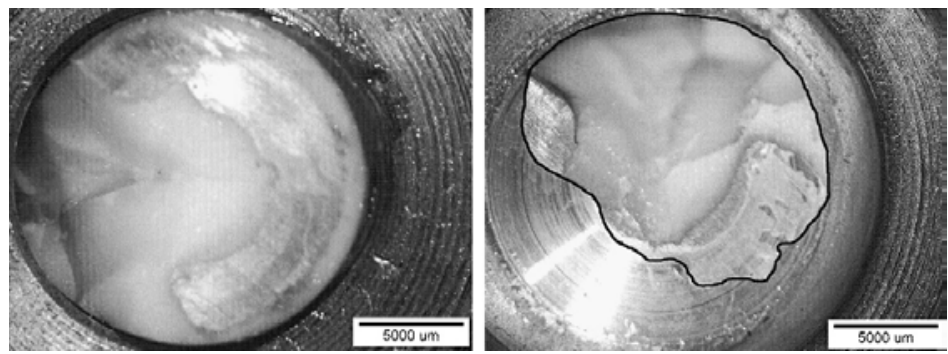

Fig. 11: Pictures of bonds destroyed during tensile tests.

In the friction welding process it is very important to get the surfaces of the two workpieces so close together that atomic forces are applied. In Fig. 12 the contact pressure distribution after the flash formation is presented. This corresponds probably to the period the bond is created. The contact pressure distribution is inhomogeneous, with the smallest values occurring at the outer areas. It means that the closeness of the bonded surfaces is non-uniform. This can also contribute to a weaker joint in the areas most distant from the axis of the welded components. 


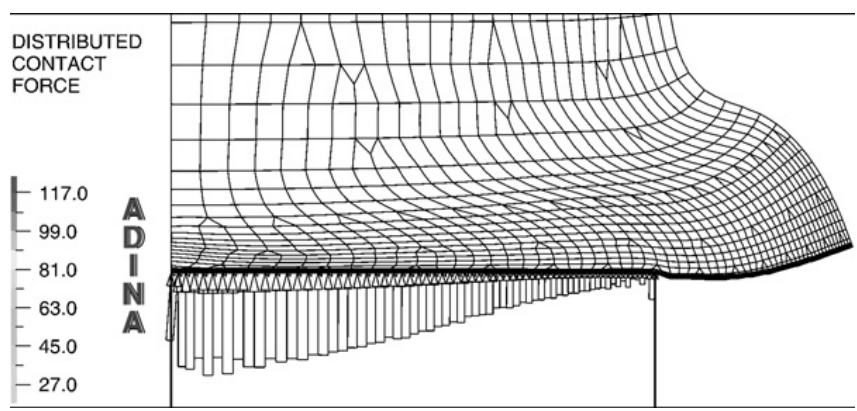

Fig. 12: Pressure distribution on the flat contact surface during the creation of the bond.

\subsubsection{The cooling phase.}

When the joint is cooled down to ambient temperature after friction welding, the thermal stresses change their signs (from a compressive stress during expansion to a tensile stress during shrinking). The unbeneficial tensile stress area enlarges during the cooling period. As a result residual stresses are generated, which is caused mainly by different physical and mechanical properties of both joined materials. In Fig. 13, calculated residual equivalent stress and axial stress in a ceramic workpiece and in the vicinity of the contact surface are shown, as function of the radial distance. Close to the central axis the equivalent stress reaches its maximum value close to $150 \mathrm{MPa}$. Axial tensile stresses also develop in that region (the maximum value reaches $120 \mathrm{MPa}$ ). This is harmful for the joint integrity since ceramic materials cannot withstand high tensile loading (and certainly not in the presence of weld impurities or defects). It was indeed observed in the tensile test that the fractured areas of the ceramic (Fig. 11) corresponds with regions of an axial tensile stress appearance. The mechanical tensile strength of the welded joints was about $30 \mathrm{MPa}$.

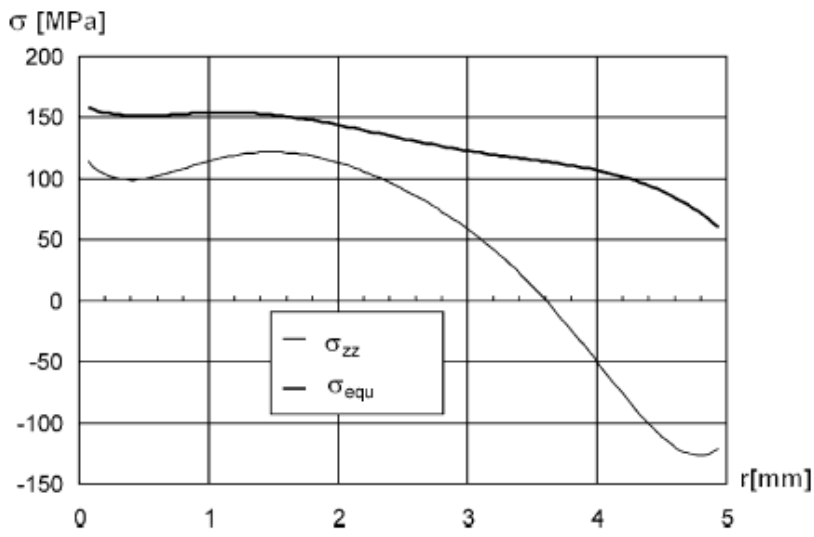

Fig. 13: Residual stress profile in a ceramic workpiece near the bond area obtained by FEM.

\section{CONCLUSIONS}

The results of this literature study show that there are two major points that are important when it comes to welding steel to a ceramic material.

- The use of an interlayer is necessary to reduce the amount of residual stresses that are induced because of the different thermomechanical properties of the workpiece. Aluminium sheet is a commonly used interlayer.

- Attention is needed to control the creation of a brittle intermetallic compound layer that grows in the aluminium-steel weld interface in proportion to the friction time.

In order to create a bond with maximum strength, these two phenomena will need to be optimized.

Once the new friction welding machine is assembled and operational we can start to put these ideas into practice. 


$\begin{array}{lll}\sigma & \text { Stress } & {[\mathrm{MPa}]} \\ \mathrm{P}_{1} & \text { Friction pressure } & {[\mathrm{MPa}]} \\ \mathrm{t}_{1} & \text { friction time } & {[\mathrm{s}]}\end{array}$

\section{ACKNOWLEDGEMENTS}

The authors would like to acknowledge the technical staff of the Belgian welding institute and Laboratory Soete for their support in building the rotary friction welding machine..

\section{REFERENCES}

1. REVIEW Friction welding - critical assessment of literature. Maalekian, M. Graz. University of Technology : Institute of Materials, Minerals and Mining, 1009 , 2007, pp. 738-759.

2. Bart Derynck, Dries Bonte. Ontwikkelen van een wrijvingslasmachine voor het verbinden van ongelijksoortige materialen. Universiteit Gent : s.n., 2010.

3. THE FRICTION JOINING OF CERAMICS TO METALS. ESSA AA, BAHRANI AS. 2, Dublin, Ireland: ELSEVIER SCIENCE SA LAUSANNE, PO BOX 564, 1001 LAUSANNE 1, SWITZERLAND, 1991, JOURNAL OF MATERIALS PROCESSING TECHNOLOGY, Vol. 26, pp. 133-140. 0924-0136.

4. Alumina-mild steel friction welded at lower rotational speeds. Mohamad Zaky Noh, Luay Bakir Hussain, Zainal Arifin Ahmad. 1-3, Malaysia: Elsevier B.V., 2007, Journal of Materials Processing Technology, pp. 279-283.

5. Mechanical behaviour of ceramics. DAVIDGE, R.W. Cambridge : Cambridge University Press, 1987.

6. Effect of interfacial reaction layer on bond strength of friction-bonded joint of Al alloy to steel. Naotsugu Yamamoto, Makoto Takahashi, Masatoshi Aritoshi, Kenji Ikeuchi. Japan : s.n., 2005. IIW Doc. IX-219006.

7. The solid phase welding of metals. Tylecote, R.F. [ed.] Edward Arnold Ltd. London : s.n., 1968, p. 154.

8. Joining aluminium to steel Part 1-Diffusion bonding. E.R.Wallach, S.Elliott and. 1981, Metal Construction, pp. 167-171.

9. Joining aluminium to steel Part 2-Friction bonding. E.R.Wallach, S.Elliott and. 1981, Metal Construction, pp. 221-225.

10. Effects of interfacial microstructure on friction-bonded strength of low carbon steel to Al-Mg alloy (AA5083). Naotsugu Yamamoto, Makoto Takahashi, Masatoshi Aritoshi, Kenji Ikeuchi. Japan : s.n., 2004, pp. 296-299. IX-2104-04.

11. Effect of interfacial reaction layer on bond strength of friction-bonded joint of Al alloyto steel. Naotsugu Yamamoto, Makoto Takahashi, Masatoshi Aritoshi, Kenji Ikeuchi. Japan : s.n., 2005. IIW Doc. IX-219006.

12. Formation of Intermetallic Compounds in Friction Bonding of Al Alloys to Steel. Naotsugu Yamamoto, Makoto Takahashi, Masatoshi Aritoshi, Kenji Ikeuchi. Japan : Trans Tech Publications, 2007, Materials Science Forum (Volumes 539 - 543), pp. 3865-3871.

13. Investigation into the properties of friction-welded aluminium bars. Bekir S. Yilbas, Ahmet Z. Sahin, Ali Coban, B.J. Abdul Aleem. Dhahran, Saudi Arabia: Elsevier science S.A., 1994, Journal of Materials Processing Technology. SSDI 0924-0136(95)01923-3.

14. Thermo-mechanical and diffusion modelling in the process. Jolanta Zimmerman, Wladyslaw Wlosinski, Zdzislaw R. Lindemann. Warsaw, Poland: Elsevier, 2009, journal of materials processing technology, pp. 1644-1653.

15. Thermo-mechanical phenomena in the process of friction welding. Z. LINDEMANN, K. SKALSKI, W. WKOSIN' SKI, and J. ZIMMERMAN. Warsaw, Poland: s.n., 2006, BULLETIN OF THE POLISH ACADEMY OF SCIENCES.

16. Residual stresses and strength of friction welded ceramic/metal joints. Weiss, R. Weinheim, Germany : s.n., march 1998, welding research supplement.

17. Advanced materials \& processes inc. metal progress. 1987.

18. REVIEW Friction welding - critical assessment of literature. Maalekian, M. Graz University of Technology : s.n., 10 09, 2007, Institute of Materials, Minerals and Mining, pp. 738-759.

19. Faes, dr. ir. K. General introduction to friction welding processes. [powerpointpresentation - Workshop on friction welding] Gent : Belgian Welding Institute, 2010.

20. AG, KUKA. KUKA, sl : sn.

21. The Effect of Joint Design and Volume Fraction on Friction Welding Properties of A360/SiC (p) Composites. C. B. LIN, C. K. MU, W. W. WU AND C. H. HUNG. Taiwan, P. R. China: Department of Mechanical Engineering, Tamkang University, 1999.

22. Smet, Jean-Pierre. Cursus Materialenleer. Hoboken : Karel de Grote-Hogeschool Antwerpen, 2008. KdG-IWT-MA-EMEM-08. 
23. Nicholas, M. G. Diffusion bonding ceramics with ductile metal interlayers. Oxfordshire, England: Material Development Division, AERE Harwell, 1986.

24. Kazakov, N.F. Diffusion Bonding of Materials. [trans.] Boris V. Kuznetsov. Moscow: Mir Publishers Moscow. 